\title{
Puromycin's effects on long-term memory and the acquisition of two successive visual discrimination tasks in Japanese quail
}

\author{
STEPHEN J. MAYOR \\ Medical College of Ohio at Toledo, P.O. Box 6190, Toledo, Ohio 43614
}

\begin{abstract}
Puromycin appears to block long-term memory of color discrimination training (measured 3 days after initial training) and inhibits its acquisition (measured as the number of days taken to reach the task criterion). The antibiotic has no effect on long-term memory of pattern discrimination, although it does affect acquisition to criterion. These results suggest that puromycin's influence on long-term memory is a function of the extent of long-term memory formation on the initial day of training as determined by task difficulty.
\end{abstract}

Antibiotics such as puromycin dihydrochloride, acetoxycycloheximide (AXM), and cycloheximide (CXM) have been used to investigate the involvement of RNA and protein synthesis with long-term memory formation. The tasks used to measure the effects of these antibiotics have been largely limited to those using aversive reinforcement. In these paradigms, the extent of training appears to influence the effect of the antibiotic on the long-term memory of that training. For example, when puromycin is injected into overtrained goldfish, there is no long-term memory blockage of avoidance training; partially trained and injected goldfish, however, do exhibit memory loss (Agranoff \& Klinger, 1969). AXM and CXM have also been reported not to be able to block long-term memory in mice trained to a criterion of 9 out of 10 correct responses on an avoidance or escape task (Flexner \& Flexner, 1966; Barondes \& Cohen, 1967b). Nevertheless, AXM appears to produce retention deficits when injected into partially escape-trained mice or avoidance-trained goldfish (Barondes \& Cohen, 1967a; Agranoff et al, 1966).

The effects of these antibiotics are not limited to aversive reinforcement tasks, however. Puromycin has also been reported to block long-term memory in quail partially trained to a successive color discrimination task using food as reinforcement (Mayor, 1969), but was ineffective in quail similarly trained to a criterion of $90 \%$ correct responses. $^{1}$ AXM was also shown to be ineffective in blocking memory in quail partially trained to a successive color discrimination using food reinforcement (Mayor, 1969).

The purpose of the experiments in this report was to investigate the interaction of such antibiotics with other aspects of behavior. For this purpose, puromycin was chosen, and its effect on the long-term memory and acquisition of a successive visual discrimination task was measured as a function of the difficulty of the task.

\section{METHOD}

\section{Animals}

Adult male Japanese quail (Coturnix coturnix japonica), which had been hatched and raised in the laboratory, were used. Body weights were maintained at $85 \%$ of the free-feed levels throughout training.

\section{Procedure}

The animals were trained to discriminate between color (Experiment I) and pattern stimuli (Experiment II) successively presented on a translucent key mounted over the food hopper in a modified pigeon test chamber (Lehigh Valley). Ten of these stimuli were presented in counterbalanced order during each training session. Each stimulus was presented for $60 \mathrm{sec}$. Interstimulus intervals lasted $15 \mathrm{sec}$, during which time the pecking key was not illuminated. The brightness of these stimuli were equated to each other. The color discrimination task used red and green stimuli (green was reinforced). The pattern discrimination stimuli were a horizontal and a vertical array of small white circles on a dark background (the vertical array was reinforced).

Correct responses were reinforced on a variable interval schedule of $30 \mathrm{sec}$ with $6.9 \mathrm{sec}$ access to food (Purina Game Bird Chow). During each reinforcement, the stimulus light was turned off and the food hopper light was turned on. All responses were recorded on digital counters. Programming equipment (Massey Dickinson) was used to operate the training chambers.

Within $5 \mathrm{~min}$ of the end of their first day's training (Day 1)-which lasted approximately $12 \mathrm{~min}$-the animals were placed in a stereotaxic apparatus and intracerebrally injected with either saline or puromycin and returned to their home cages for 3 days. A microsyringe (Hamilton) with a 30-ga needle was used to inject 10 microliters of the appropriate solution at each of four sites. Two injections were made into each hemisphere to a depth of $3 \mathrm{~mm}$. Unilateral sites were $3 \mathrm{~mm}$ from midline. The rostral sites were $2 \mathrm{~mm}$ anterior, while the caudal sites were $1 \mathrm{~mm}$ posterior to the interaural line. All injections were made slowly and were complete within 5 min of the last training trial.

Puromycin was prepared in $0.9 \%$ saline and adjusted to $\mathrm{pH} 7$ with $1 \mathrm{~N} \mathrm{NaOH}$. The experimental groups in the color discrimination task received 45 and 180 micrograms/site of puromycin. (A third experimental group trained to the color discrimination task received 90 micrograms/site. However, this group was not included in the analysis because their body weights were maintained at $75 \%$ of their free-feed weights $-10 \%$ lower than all other groups in this experiment.) The experimental group in the pattern discrimination task received $90 \mathrm{micrograms} / \mathrm{site}$. Both saline groups were injected with $0.9 \%$ physiological saline solution in order to control for possible trauma caused by the injection procedure.

On the 4 th day, training was resumed and continued daily thereafter until the criterion of $90 \%$ correct responses (100 times the sum to the reinforced stimulus divided by the number of 
Table 1

Mean ( \pm SD) Percentage of Correct Responses and Days to Criterion for the Acquisition of a Successive Color Discrimination Task*

\begin{tabular}{|c|c|c|c|c|}
\hline \multirow{2}{*}{$\begin{array}{l}\text { Group } \\
(\mu \mathrm{g} / \mathrm{Site})\end{array}$} & \multirow{2}{*}{$\begin{array}{c}\text { Number } \\
\text { of Quail }\end{array}$} & \multicolumn{2}{|c|}{ Percentage of Correct Responses } & \multirow{2}{*}{$\begin{array}{c}\text { Days to } \\
\text { Criterion } \dagger\end{array}$} \\
\hline & & Day 1 & Day 4 & \\
\hline $\begin{array}{l}\text { Saline } \\
\text { Puromycin (45) } \\
\text { Puromycin (180) }\end{array}$ & $\begin{array}{l}39 \\
13 \\
10\end{array}$ & $\begin{array}{c}61 \pm 16 \\
60 \pm 14 \\
58 \pm 20 \\
F=0.23 \\
\text { p n.s. }\end{array}$ & $\begin{aligned} 78 & \pm 16 \\
66 & \pm 14(2.36) \dagger \\
60 \pm 16 & (3.36) \dagger \dagger \\
F & =7.00 \\
p & <.005\end{aligned}$ & $\begin{array}{c}5.3 \pm 1.7 \\
6.7 \pm 1.8(-2.55) \dagger \\
7.3 \pm 1.0(-3.34) \dagger \dagger \\
F=7.25 \\
p<.005\end{array}$ \\
\hline
\end{tabular}

${ }^{*} d f=2 / 59 \quad t_{p}<.025 \quad t_{t} p<.005$ (one-tailed Dunnett's $t$ test). Significant $t$ scores are given in parentheses. $F$ ratios and their respective levels of significance for an analysis of variance for a single variable of classification are given for each measure at the bottom of their respective columns.

total responses) was reached for 2 consecutive days.

Twenty-five animals for pattern discrimination training were selected at random from among the 39 controls of the color discrimination task after they had reached criterion on that task.

\section{RESULTS}

The puromycin-treated animals performed at significantly lower levels than the control animals on the 2nd day of training (Day 4) and in the acquisition of the color discrimination task (days to criterion) (Table 1). The deficit in performance is attributed to puromycin's influence on long-term memory. Motor or motivational changes do not appear to be involved, because an analysis of cumulative response curves, total responses, and body weight reveals no significant differences between the groups. In addition, previously reported experiments (Mayor, 1969), using overtrained animals,

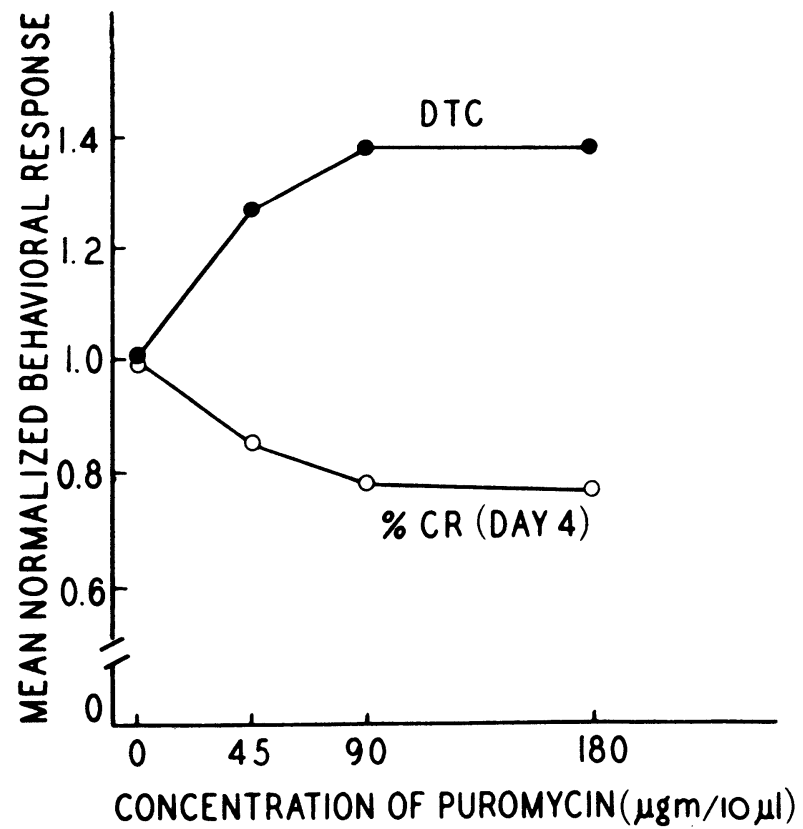

Fig. 1. Normalized Day 4 percentage correct response (percent CR) and days to criterion (DTC) for a successive color discrimination task as a function of the concentration of puromycin. show no effect of puromycin on long-term memory as measured by performance. Puromycin has also been shown to facilitate reversal learning of the paradigm used in this report; thus, the action of the antibiotic cannot be attributed to any toxic effect (Mayor, 1969). It is difficult to imagine a toxic substance inhibiting one task and then facilitating its reversal.

Although the puromycin group $(\mathrm{N}=22)$, injected with 90 micrograms/site, was not used in this analysis, because of $10 \%$ lower body weights, their performance on Day $4(\mathrm{t}=4.38, \mathrm{p}<.005)$ and on days to criterion $(\mathrm{t}$ $=4.03, \mathrm{p}<.005$ ) was significantly lower than that of control animals. For illustrative purposes only, the data for this group were included along with the data from Table 1 and then normalized against the saline controls (Fig. 1). Puromycin of zero concentration corresponds to the saline control group. This dose-response curve appears to indicate that at doses of greater than 90 micrograms/site, puromycin's influence on color discrimination training does not increase. However, this interpretation must be tempered by the realization that the 90-microgram/site group's body weights were substantially lower $(10 \%)$ than those of the other groups used in these experiments.

Puromycin injected into experimental animals immediately after training to a pattern discrimination had no effect on long-term memory, measured by performance on Day 4 (Table 2). However, the experimental group took significantly longer to reach criterion than the controls. Again, as above, an analysis of response curves, etc., indicates that puromycin is not influencing motor function or motivation.

The difficulty of the pattern discrimination is illustrated by comparing the results listed in Tables 1 and 2. On the first day's training, all groups were about $10 \%$ better than chance on the color discrimination, while on the pattern discrimination they only reached chance. This is particularly interesting inasmuch as these animals were competent performers on an almost identical task. A comparison of the Day 4 performance of the saline group trained to a color discrimination with that of the saline group trained to a pattern discrimination also reveals the difficulty of the latter task. On the color discrimination, the performance 
Table 2

Mean ( \pm SD) Percentage of Correct Responses and Days to Criterion for the Acquisition of a Successive Pattern Discrimination*

\begin{tabular}{|c|c|c|c|c|}
\hline \multirow{2}{*}{$\begin{array}{l}\text { Group } \\
(\mu \mathrm{g} / \mathrm{Site})\end{array}$} & \multirow{2}{*}{$\begin{array}{l}\text { Number } \\
\text { of Quail }\end{array}$} & \multicolumn{2}{|c|}{ Percentage of Correct Responses } & \multirow{2}{*}{$\begin{array}{l}\text { Days to } \\
\text { Criterion }\end{array}$} \\
\hline & & Day 1 & Day 4 & \\
\hline Saline & 12 & $48 \pm 13$ & $51 \pm 13$ & $9.4 \pm 2.4$ \\
\hline Puromycin $(90)$ & 13 & $\begin{array}{l}48 \pm 13 \\
F=0.00 \\
p \text { n.s. }\end{array}$ & $\begin{array}{l}47 \pm 13 \\
F=0.76 \\
p \text { n.s. }\end{array}$ & $\begin{array}{c}13.1 \pm 4.1 \quad(-2.73) \div \\
F=7.40 \\
p<.025\end{array}$ \\
\hline
\end{tabular}

$* d f=1 / 23 \quad t p H .01$ (one-tailed student's $t$ test). Significant $t$ scores are given in parentheses. F ratios and their respective levels of significance for an analysis of variance for a single variable of classification are given for each measure at the bottom of their respective columns.

improves about $17 \%$ between Day 1 and Day 4 , but on the pattern discrimination there is no significant improvement over the same time period. It also takes the saline group almost twice as long to acquire a pattern discrimination as to acquire a color discrimination (i.e., 9.4 vs 5.3 days).

\section{DISCUSSION}

A comparison of Experiment I to Experiment II reveals certain dissimilarities in the dosages of puromycin used. Most notable is the absence of puromycin at a dose level of 180 micrograms/site in the pattern discrimination task. While it may be reasonably argued that a complete design should include all dose levels, the results of Experiments I and II, using puromycin at a dosage of 90 micrograms/site, made it unnecessary to continue with larger doses in Experiment II. Table 1 shows that the effect of the highest dose of puromycin (i.e., the highest dose that could be used with zero mortality) is to return the level of performance on Day 4 to that of a naive animal on Day 1. Figure 1 shows that the effect of puromycin on long-term memory and on acquisition (days to criterion) appears to plateau at a dosage of 90 micrograms/site. Consequently, when the performance of the puromycin group on Day 4 of the pattern discrimination was found to be no better (or worse) than on Day 1, it was concluded that there would be no advantage to be gained by doubling the dosage of puromycin. If puromycin acts on memory, then it cannot produce a lower level of performance than that of a "naive" animal-an effect already achieved at the dosage of $90 \mathrm{micrograms} / \mathrm{site}$. In addition, it was felt that doubling the dosage of puromycin in the pattern discrimination would not contribute substantially to the effect it had demonstrated on the acquisition phase of the experiment. At the given dosage, the days to criterion measure was significantly different from that of the control group and in the same direction as in the color discrimination task. Hence, doubling the dosage in Experiment II was not expected to reveal anything new and, in consideration of the time and expense involved in adding an additional group, was judged not to be sufficiently worthwhile to pursue.

In order to understand the differential effect of puromycin on the long-term memory and acquisition of the two successive visual discrimination tasks used in the above experiments, the following model was formed. In this model, each exposure to training forms a certain amount of engram or long-term memory. Engram formation occurs through consolidation of short-term memory brought on by the learning experience. The rate of engram formation at any instant in time approximates the slope of the learning curve. Initially, the rate of engram formation is high, but after some time, as in the case of the learning curve, it plateaus or becomes zero. The amount of engram formed at any one time is directly proportional to the length of the learning trial and inversely proportional to the difficulty of the task. Within limits, increasing the length of the learning trial for a given task increases the reliability of performance, because more engram is made than in a shorter trial. Similarly, the easier the task, the faster the consolidation and the greater the amount of engram formation. The reliability of performance (i.e., recall) of the task is a function of the amount of engram formed at any given time.

In terms of this model, then, it appears that puromycin's influence on long-term memory (Day 4) is measurable only when there is sufficient amount of engram formed to give some reliability in performance, as in the case of the color discrimination task. The model also appears to predict the dose-response nature of puromycin illustrated in Fig. 1. If performance reliability is quantitatively related to engram formation, then increasing the dosage of puromycin would be expected to decrease performance reliability (i.e., long-term memory) since more engram would be affected. Thus, when the dosage of puromycin reaches a certain level, which is sufficiently high to interact with all the recently formed engram, the animal's performance should be no different than a naive animal's. This appears to be the case with the highest dose of puromycin used in the color discrimination task (cf. Table 1). Consequently, this group should also take longest to reach the task criterion, since it would have the least amount of engram to build on to insure 
performance reliability. This also appears to be the case (cf. Table 1).

Although the amount of engram formed in the first day of pattern discrimination training is unmeasurable in terms of puromycin's blocking performance on Day 4, the experimental group still took longer to reach task criterion than the control group. There are two possible explanations:

(1) Puromycin interfered with memory, but engram formation was too low to detect this action on Day 4. However, a sufficient amount appears to have been formed and interfered with to be manifestable as an increase in the length of time to reach criterion.

(2) Products of puromycin metabolism, such as peptidyl-puromycin, may be present for some time after injection on Day 1 and, thus, may be influencing subsequent training. However, data from reversal training (Mayor, 1969) argues against this last possibility, since puromycin-injected animals had less proactive inhibition on Day 4 (the first day of reversal) and reached the task criterion faster than saline-injected animals.

The lack of an effect of an antibiotic on animals trained to a 9 out of 10 correct response criterion or on overtrained animals, as reported in the literature, is attributed, according to the model, to the inability of the antibiotic to influence the extensive amount of engram formed.

\section{REFERENCES}

Agranoff, B., \& Klinger, P. Puromycin effect on memory fixation in the goldfish. Science, 1964, 146, 952-953.

Agranoff, B., Davis, R., \& Brink, J. Chemical studies on memory fixation in goldfish. Brain Research, 1966, 1, 303-309.

Barondes, S., \& Cohen, H. Comparative effects of cycloheximide and puromycin on cerebral protein synthesis and consolidation of memory in mice. Brain Research, 1967a, 4, 44-51.

Barondes, S., \& Cohen, H. Delayed and sustained effect of acetoxycycloheximide on memory in mice. Proceedings of the National Academy of Science (U.S.), 1967b, 58, 157-164.

Flexner, L., \& Flexner, J. Effect of acetoxycycloheximide and of an acetoxycycloheximide-puromycin mixture on cerebral protein synthesis and memory in mice. Proceedings of the National Academy of Science (U.S.), 1966, 55, 369-374.

Mayor, S. Memory in the Japanese quail: Effects of puromycin and acetoxycycloheximide. Science, 1969, 166, 1165-1167.

\section{NOTE}

1. S. Mayor, unpublished research, 1968.

(Received for publication April 13, 1972; revision received September 18, 1972.) 